\title{
Inflation and relative price variability in Mexico: the role of remittances
}

\author{
J. Ulyses Balderas and Hiranya K. Nath* \\ Department of Economics and International Business, Sam Houston State \\ University, Huntsville, TX 77341-2118, USA
}

This article derives generalized impulse responses from the estimation of a vector autoregression (VAR) model using monthly data between 1995 and 2005 for Mexico, to examine the inflation-relative price variability (RPV) relationship, and to investigate if remittances could account for the observed relationship. While the positive relationship between inflation and RPV is a robust result, remittances are found to have significant positive effects on both inflation and RPV. These results are interpreted as providing evidence in support of our intuition that remittances could be responsible for generating a positive relationship between inflation and RPV.

\section{Introduction}

The existence of a positive correlation between inflation and relative price variability (RPV) is a well-documented empirical regularity. ${ }^{1}$ The theories that have been proposed to explain this relationship are not settled in regards to the causal mechanism that generates such a relationship. These theories can broadly be divided into three categories: (i) theories that show the causation running from inflation to RPV; (ii) those that take RPV as exogenous and show that inflation is caused by the distribution of relative price changes and (iii) theories that hold that both inflation and RPV are generated by some common factor. $^{2}$

In this article, we examine the inflation-RPV relationship in Mexico, and investigate if remittances could be one of those factors that generate the observed relationship for consumer prices. There have been manifold increases in the flow of remittances into Mexico in recent years and these remittances are expected to have multitude of effects in the economy. ${ }^{3}$ Studies have shown that a large number of households which constitute a significant part of the total population of Mexico receive remittances. ${ }^{4}$ Zarate-Hoyos (2004) reports that remittance receiving households receive an average amount of $\$ 476$ per month. It has been suggested that families of modest means having no access to credit are likely to spend most of these remittances to finance large consumer expenditures such as furniture, appliances, housing, medical care and education. In fact, some studies (e.g. Durand et al., 1996) find that almost three quarters of total reported remittances are spent on consumption. Thus, it is reasonable to argue that demand for such items will increase relatively more

*Corresponding author. E-mail: eco_hkn@shsu.edu

${ }^{1}$ In the literature, RPV is measured by the SD of relative price changes across commodities/sectors.

${ }^{2}$ For a brief survey of the literature, see, for example, Chang and Cheng (2002) and Nath (2004).

${ }^{3}$ According to official estimates, total remittances have increased from about 3.67 billion in 1995 to $\$ 20.03$ billion in $2005-$ by more than 5 times (based on authors' estimates from Banco de Mexico data).

4 'There were approximately 1.3 million households in Mexico receiving remittances in 2000. Over $10 \%$ of households in rural areas receive remittances, and for these households remittances represent almost $48.9 \%$ of their total current monetary income. In urban areas, over $4 \%$ of households receive remittances that account for almost $50 \%$ of their current monetary income' (Zarate-Hoyos, 2004). 
than that for other items. These shifts in demand, combined with price elasticities of supply, may then imply disproportionate changes in relative prices. This is likely to increase the dispersion of relative price changes. Furthermore, remittances may raise overall inflation through their direct and indirect effects on aggregate demand. ${ }^{5}$

In this article, generalized impulse responses derived from the vector autoregression (VAR) framework applied to Mexican data for the period from 1995 to 2005 indicate that the positive relationship between inflation and RPV is a robust result. We also find that remittances have significant positive effects on both inflation and RPV which, in turn, suggest that remittances could at least partially be responsible for a positive relationship between inflation and RPV.

The rest of the article is organized as follows. Section II describes our data and empirical methodology. In Section III, we present and discuss the results. The next section includes our concluding remarks.

\section{Data and Empirical Methods}

\section{Data}

The main source of data for this study is the Banco de México's (2006) database on the Economic and Financial Indicators. We obtain monthly data on remittances and consumer price indices (CPI) for a period from January 1995 to December 2005. Our choice of 1995 as the start date for our sample period is dictated by our desire to avoid the disturbances created by the economic crisis of $1994 .{ }^{6}$ The remittances data are available in millions of US dollars, and have been converted into millions of pesos using the nominal exchange rate (pesos per dollar). We use the CPI for a total of 77 consumer items that include both goods and services. We also obtain monthly data on industrial production index as a measure of output, and on M1 as a measure of money supply. Additionally, we retrieve monthly data on the government expenditures from the
National Accounts System published by Mexican Bureau of Statistics (INEGI, 2006). ${ }^{7}$

We first calculate measures of inflation and RPV using the CPI data. Let $P_{t}$ be the aggregate CPI in period $t$, then aggregate inflation is defined as

$$
\pi_{t}=100 \times\left(\ln P_{t}-\ln P_{t-1}\right)
$$

Furthermore, let $P_{i, t}$ be the CPI of consumption item $i$ in period $t$. Then the change in price of $i$ in period $t$ is defined as

$$
\pi_{i, t}=100 \times\left(\ln P_{i, t}-\ln P_{i, t-1}\right)
$$

$\mathrm{RPV}$ in period $t$ is defined as

$$
V_{t}=\sqrt{\frac{1}{n-1} \sum_{i=1}^{n}\left(\pi_{i, t}-\bar{\pi}_{t}\right)^{2}}
$$

where $\bar{\pi}_{t}=(1 / n) \sum_{i=1}^{n} \pi_{i, t}$ is the mean price changes (averaged across consumption items) in period $t .^{8}$ Note that $n$ is the number of consumption items. We also calculate the percentage growth rates of remittances, money supply, government expenditures, nominal exchange rate and industrial production as 100 times the log first differences of the respective variables.

\section{Empirical methods}

We use a VAR methodology to model the dynamic relationships between inflation, RPV and remittances. This approach allows us to nest all three strains of theoretical explanations of the inflationRPV relationship. We derive generalized impulse responses from the estimates of two different specifications of the following unrestricted VAR model:

$$
Y_{t}=A_{0}+\sum_{j=1}^{p} A_{j} Y_{t-j}+\varepsilon_{t}
$$

where $Y_{t}$ is an $m \times 1$ vector of variables; $A_{0}$ is an $m \times 1$ vector of constants; $A_{j}$ is an $m \times m$ matrix of auto-regressive coefficients at lag $j . p$ is the maximum lag of the variables chosen by using a 'pare down' method based on Schwarz Information Criterion (SIC). ${ }^{9} \varepsilon_{t}$ is an $m \times 1$ vector of innovations that are

\footnotetext{
${ }^{5}$ Adelman and Taylor (1992) find that when all direct and indirect effects are taken into account, each dollar of remittances spent on consumption increases the Mexican gross domestic product by $\$ 2.90$.

${ }^{6}$ Also, though monthly data on remittances are available since 1980, because of various limitations in data collection process, they are less complete and, therefore, not very reliable for the early period of this process.

${ }^{7}$ The data series have been adjusted for seasonal movements, wherever necessary, using the US Census Bureau's X12 seasonal adjustment program. For a brief description, you may consult the EViews User Guide (1994).

${ }^{8}$ Note that $P_{t}$ is constructed as a weighted index of all underlying prices and, therefore, it is desirable that both $V_{t}$ and $\bar{\pi}_{t}$ are calculated as weighted SD and mean, respectively. However, we find that the results do not change. Moreover, some prominent studies for the United States (e.g. Vining and Elwertowski, 1976) use unweighted measures.

${ }^{9}$ We begin with a lag length of approximately $T^{1 / 3}$. See Enders (2004), p.358.
} 
assumed to be serially uncorrelated, but can be correlated with each other. Unlike 'orthogonalized' impulse responses that are commonly used to conduct dynamic analysis of VAR models, the generalized impulse responses approach is invariant to the ordering of the variables in the VAR (Pesaran and Shin, 1998).

\section{Results}

We estimate two specifications of the model described by Equation 4. The most parsimonious specification includes only three variables: remittance growth, inflation and RPV. ${ }^{10}$ The idea is to focus on the dynamic interactions among the three variables of interest. A more general specification, however, includes four additional variables: money growth, government expenditure growth, nominal exchange rate growth and industrial production growth. The first two variables are included to capture and control for the effects of monetary and fiscal policies on inflation and relative prices. The changes in nominal exchange rate may affect inflation and RPV through their effects on international trade that has implications for aggregate demand. Inclusion of growth of industrial production allows for the possibility that real shock influences the rate of inflation through a 'Phillips curve' type relationship. ${ }^{11}$

The estimated generalized impulse responses (along with two standard error bands) of inflation and RPV derived from our parsimonious specification of the model are presented in Fig. 1. The first row shows responses of inflation to a one standard deviation innovation in RPV, and of RPV to a one standard deviation innovation in inflation. An innovation in RPV leads to a positive and fairly persistent increase in inflation and vice versa. These responses are consistent with the empirical observation of a positive relationship between inflation and RPV. The second row shows the responses of inflation and RPV to a one standard deviation innovation in remittance growth. An innovation in remittance growth leads to a statistically significant positive increase in inflation, that peaks in period 2 (about 0.2 percentage points) and then this positive effect gradually tapers off. The effects on RPV have very similar pattern though the magnitudes of these positive effects are much smaller. These results suggest that remittances may be (at least partially) responsible for generating a positive relationship between inflation and RPV. ${ }^{12}$ They seem to support our intuition, and are consistent with the findings of others. ${ }^{13}$

We now include money growth, government expenditure growth, exchange rate growth and industrial production growth in addition to the three variables of interest, and estimate a more general specification of our VAR model. Note that except for exchange rate, all other growth rates have been adjusted for CPI inflation. ${ }^{14}$ The generalized impulse responses of inflation and RPV are shown in Fig. 2. As we can see from the first row, innovations in inflation and RPV have significant positive effects on each other, which demonstrate once again the positive relationship between the two. The responses of inflation and RPV to remittances are very similar to those in Fig. 1 though the magnitudes are slightly smaller.

\section{Concluding Remarks}

We derive generalized impulse responses from the estimation of a VAR model using monthly data between 1995 and 2005 for Mexico, to examine the inflation-RPV relationship, and to investigate if remittances could potentially explain the observed relationship. While the positive relationship between inflation and RPV is a robust result, remittances are found to have significant positive effects on both

\footnotetext{
${ }^{10}$ We first conduct augmented Dickey-Fuller test to determine the order of integration for each of the variables. The null hypothesis of a unit root has been rejected in all cases implying stationarity. Interested readers may obtain the test results from the authors.

${ }^{11}$ In a 'somewhat related' study, Rogers and Wang (1993) find that output, monetary and exchange rate shocks are the most important sources of fluctuations in relative prices in Mexico. They, however, use the ratio of the wholesale price index (WPI) to the consumer price index $(\mathrm{CPI})$ as the measure of relative prices.

${ }^{12}$ Note that for this result, remittances are not required to have positive effects on inflation and on RPV. As long as they have similar effects on both, they will generate a positive relationship.

${ }^{13} \mathrm{We}$ also estimate the model using data for a longer period starting in 1980 . We do not find any significant effect of remittances on either inflation or RPV. As discussed before, the data on remittances during the 1980s and early 1990s were incomplete and not very reliable. However, we find evidence in support of a positive relationship between inflation and RPV even for this extended period of time.

${ }^{14}$ Similar specification can be found in previous studies. For example, Rogers and Wang (1995) include nominal exchange rate in addition to the real variables in the VAR model they estimated to investigate the sources of relative price changes in six high-inflation countries.
} 

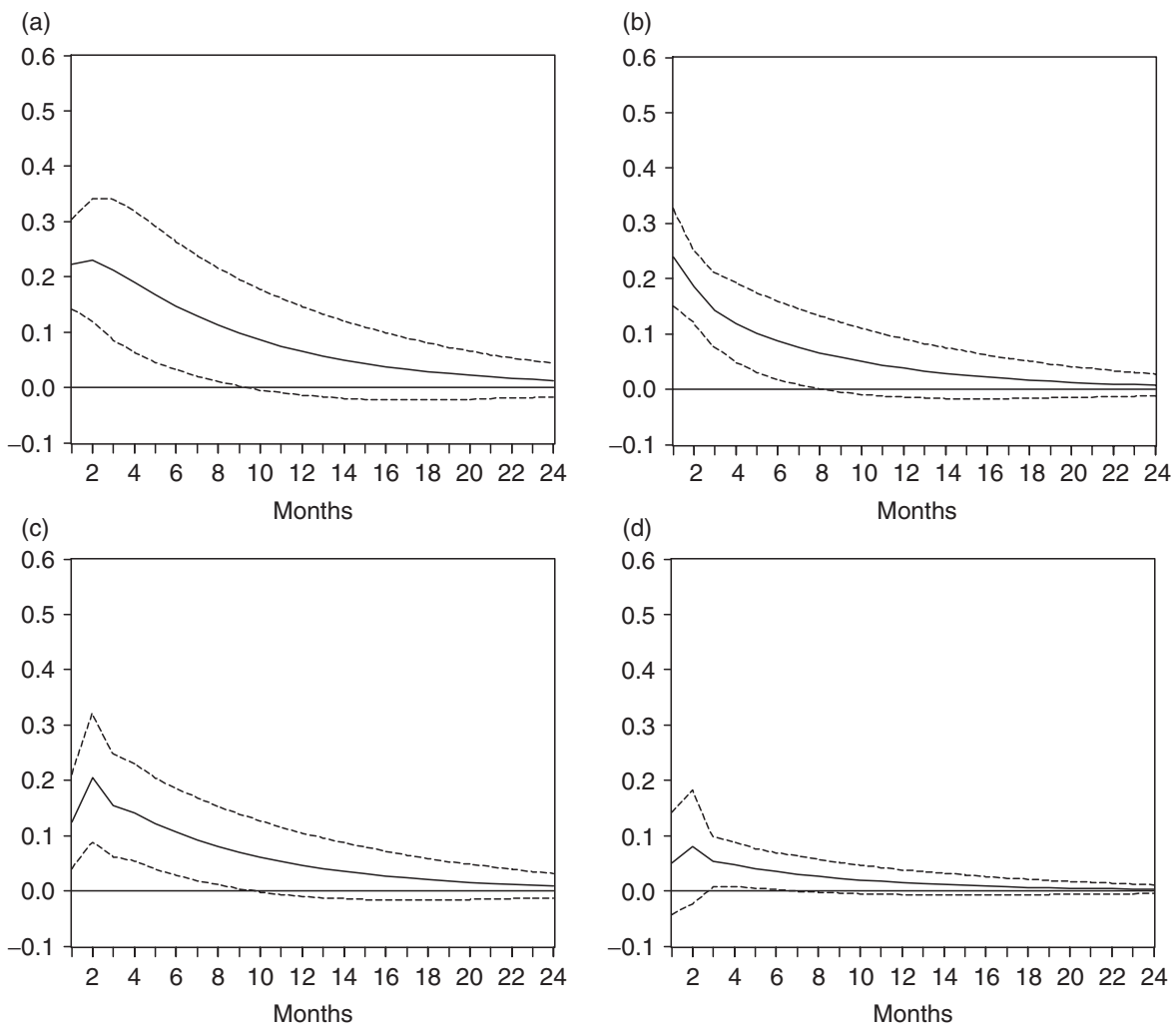

Fig. 1. Responses to generalized one standard deviation innovations $\pm 2 \mathrm{SE}$ derived from parsimonious specification of VAR model. (a) Response of inflation to RPV. (b) Response of RPV to inflation. (c) Response of inflation to remittances; (d) Response of RPV to remittances
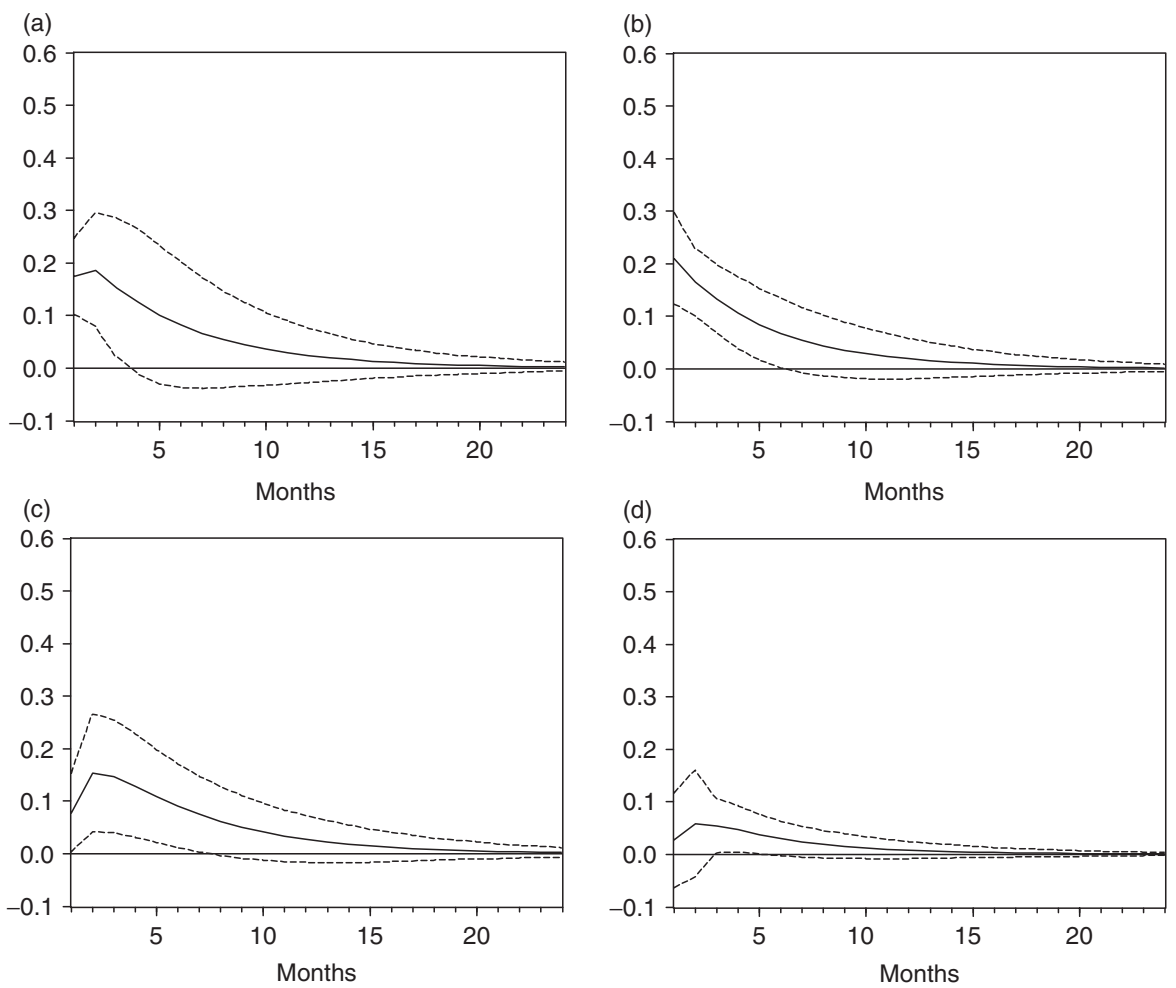

Fig. 2. Responses to generalized one standard deviation innovations $\pm 2 \mathrm{SE}$ derived from general specification of VAR model. (a) Response of inflation to RPV. (b) Response of RPV to inflation. (c) Response of inflation to remittances. (d) Response of RPV to remittances 
inflation and RPV. Thus, there is some evidence to support our intuition that remittances could generate a positive relationship between inflation and RPV.

However, these results are only suggestive. In order to take full account of the effects of remittances on the distribution of relative prices, the future research proposes to examine the effects of remittances on each price separately rather than on an aggregate measure of relative dispersion.

\section{Acknowledgements}

An earlier version of this article was presented at the 75th Annual Meeting of the Southern Economics Association in Washington, D.C. November 18-20, 2005. We would like to thank Catalina AmuedoDorantes and other members of the audience for many useful comments.

\section{References}

Adelman, I. and Taylor, J. E. (1992) Is structural adjustment with a human face possible? The case of Mexico, Journal of Development Studies, 26, 387-407.

Banco De Mexico. Economic and Financial Indicators. Available online at <http://www. banxico.org.mx/siteBanxicoINGLES/eInfoFinanciera/ FSinfoFinanciera.htm $>$ (accessed 16 March 2006).
Chang, E. C. and Cheng, J. W. (2002) Inflation and relative price variability: a revisit, Applied Economics Letters, 9, 325-30.

Durand, J., Kandel, W., Parrado, E. A. and Massey, D. S. (1996) International migration and development in Mexican communities, Demography, 33, 249-64.

Enders, W. (2004) Applied Econometric Time Series, 2nd edn, John Wiley \& Sons, Inc., New York.

INEGI. Sistema de Cuenats Nacionales. Available online at $<$ http://dgcnesyp.inegi.gob.mx/cgi-win/bdieintsi.exe/ NIVM10\#ARBOL > (accessed 16 March 2006).

Nath, H. K. (2004) Relative importance of sectoral and aggregate sources of price changes, Applied Economics, 36, 1781-96.

Pesaran, H. M. and Shin, Y. (1998) Generalized impulse response analysis in linear multivariate models, Economics Letters, 58, 17-29.

Quantitative Micro Software (1994) EViews4 User's Guide

Rogers, J. H. and Wang, P. (1993) Sources of fluctuations in relative prices: evidence from high inflation countries, Review of Economics and Statistics, 75, 589-605.

Rogers, J. H. and Wang, P. (1995) Output, inflation, and stabilization in a small open economy: evidence from Mexico, Journal of Development Economics, 46, 271-93.

Vining, D. R. and Elwertowski, T. C. (1976) The relationship between relative prices and the general price level, American Economic Review, 66, 699-708.

Zarate-Hoyos, G. A. (2004) Consumption and remittances in migrant households: toward a productive use of remittances, Contemporary Economic Policy, 22, 555-65. 